de $\alpha \leq 0,05$. A análise estatística foi feita pelo teste $t$ de Student, Mann-Whitney e coeficiente de Pearson para correlações.

Resultados: Nas 21 pacientes com PE a média do $\mathrm{V}_{\max }$ foi de $982,69 \mu \mathrm{mol} / \mathrm{L}$ de céls/h enquanto a média para as gestantes normais foi de 584,73 $\mu \mathrm{mol} / \mathrm{L}$ de céls $/ \mathrm{h}$. O $\mathrm{K}_{\mathrm{m}}$ foi de $59,31 \mu \mathrm{mol} / \mathrm{L}$ nas $\mathrm{PE}$ e de 59,46 $\mu \mathrm{mol} / \mathrm{L}$ nas normais. Houve correlação das variáveis clínicas com o $\mathrm{V}_{\max }$ e não com o $\mathrm{K}_{\mathrm{m}}$. Conclusões: o $\mathrm{V}_{\max }$ foi maior nas pacientes com $\mathrm{PE}$ quando comparada com gestantes normais. Houve correlação das variáveis clínicas com o $\mathrm{V}_{\max }$ e não com o $\mathrm{K}_{\mathrm{m}}$.

Palavras-chave: Gravidez normal. Hipertensão na gravidez, investigação e tratamento.

Expressão Endometrial das Proteinas de Membrana Reguladoras do Sistema Complemento CD59, DAF, MCP e CR1 em Mulheres Normais e Naquelas Submetidas à Hiperestimulação Ovariana

Autor: Rosana Rita N. Fonzar Marana

Orientador: Prof. Dr. Rui Alberto Ferriani

Dissertação de Mestrado, apresentada à Faculdade de Medicina de Ribeirão Preto da Universidade de São Paulo, na Área de Tocoginecologia, em 11/03/99.

Introdução: Os tecidos do trato reprodutivo expressam e sintetizam componentes do sistema complemento (SC) ao longo do ciclo menstrual, em estreita correlação com os niveis hormonais, o que sugere a necessidade de controle de sua ativação. Os ciclos submetidos à hiperestimulação ovariana podem apresentar modificações na expressão dessas proteínas em decorrência das altas concentrações hormonais.

Objetivos: Avaliar a expressão endometrial das proteínas reguladoras do $\mathrm{SC}$ ao longo do ciclo menstrual normal e de pacientes submetidas a hiperestimulação ovariana (HO) para fins de fertilização assistida e transferência de embriões (FIV-TE).

Casuística e Métodos: Foram avaliadas a expressão do CD59, DAF, MCP e CR1, no endométrio de 32 mulheres normais durante as diferentes fases do ciclo menstrual e de 10 pacientes submetidas à HO durante a fase lútea intermediária através da técnica de imuno-histoquímica.

Resultados: O CD59 como o DAF, se expressaram no endométrio durante a fase secretora, em ambos os grupos de mulheres. O CD59 teve marcação mais intensa na fase secretória intermediária enquanto que o DAF, nas fases secretória intermediária e tardia. Houve expressão da MCP no epitélio glandular em todo o ciclo menstrual, com diminuição na subfase proliferativa intermediária. O CR1 não foi detectado em nenhum dos grupos. Não houve marcação para nenhum anticorpo estudado, no estroma endometrial.

Conclusões: As proteínas reguladoras do SC, CD59, $\mathrm{DAF}$ e MCP estão presentes no endométrio humano normal e naqueles hiperestimulados, com exceção do CR1. A subfase em que o CD59 foi demonstrado sugere que o mesmo tenha grande importância durante o processo de implantação do embrião. O DAF, da mesma forma, deve contribuir para que ocorra a nidação e o início da gestação de modo adequado, através do controle do SC.

Palavras-chave: Endométrio, investigação, Ciclo menstrual.

\title{
Mulheres Infectadas pelo HIV: 0 Impacto na Anticoncepção, no Comportamento Sexual e na
} História Obstétrica

Autor: Jarbas Magalhães

Orientador: Prof. Dr. Paulo César Giraldo

Dissertação de Mestrado apresentada ao Curso de Pós-Graduação em Medicina, área de Tocoginecologia da Faculdade de Ciências Médicas da Universidade Estadual de Campinas, para obtenção do título de Mestre em Medicina, em 30/9/98. 